\title{
IMAGENS DO MIGRANTE NA MÚSICA POPULAR BRASILEIRA
}

Celso F. Favaretto*

D a conhecida canção de Dorival Caymmi, "Peguei um Ita no Norte", que se tornou emblemática; à pouco conhecida "No Dia em que eu vim-me embora", de Cactano Veloso, a saga dos nordestinos que vêm para o Sul, acreditando "na fama e no dinheiro para ser feliz"'(1), atravessa a música popular brasileira das décadas de 50 e 60 compondo um imaginário de exílio e saudade, de esperança e decepção. Incidindo, especialmente, na vida do homem simples e pobre, marcado pela seca $\mathrm{c}$ miséria, sem futuro na terra que tanto ama, otema do retirante comparecenas músicas com uma força semelhante (embora justificada por outros aspectos da análise social) ao deslocamento, na década de 30 , de escritores e artistas do Norte/Nordeste, Bahia e Minas para o Rio. Analisando o acontecimento, bradou um crítico da época: "são os do Norte que vêm", como que valorizando a interferência e as mudanças de registro que provocavam na literatura.

As conções do período em destaque desdobram um imaginário vinculado simultaneamente a umá mitologia de origem (concepção edênica da "terra", votada à felicidade) e a uma utopia de progresso (o Sul apontando o futuro, como resolução de problemas imediatos e das condições de possibiliade de volta ao Norte). Norte e Sul são substancializados; são metáforas de pobreza e riqueza, imagens de atraso e progresso, articulando sempre a decisão de ir e o anelo de voltar. Entre a ilusão e a desilusão, imagens recorrentes na maioria das músicas, o Sul aparece como o lugar do trabalho e da espera, do lamento e da saudade: "Hoje longe muitas léguas/ Numa triste solidão/Espero a chuva cair de novo/ Pra mim vortá pro meu sertão"'(2).

Entretanto, ainda que esse imaginário seja muito cristalizado, há diferenças e ambiguidades que modalizam o tema da ida e da volta, pois ora as músicas reme- tem-se a uma mitologia coletiva, ora procedem de mitologizações individuais(3). As- sim, embora esquematicamente, pode-se classificar as canções em três tipos, que

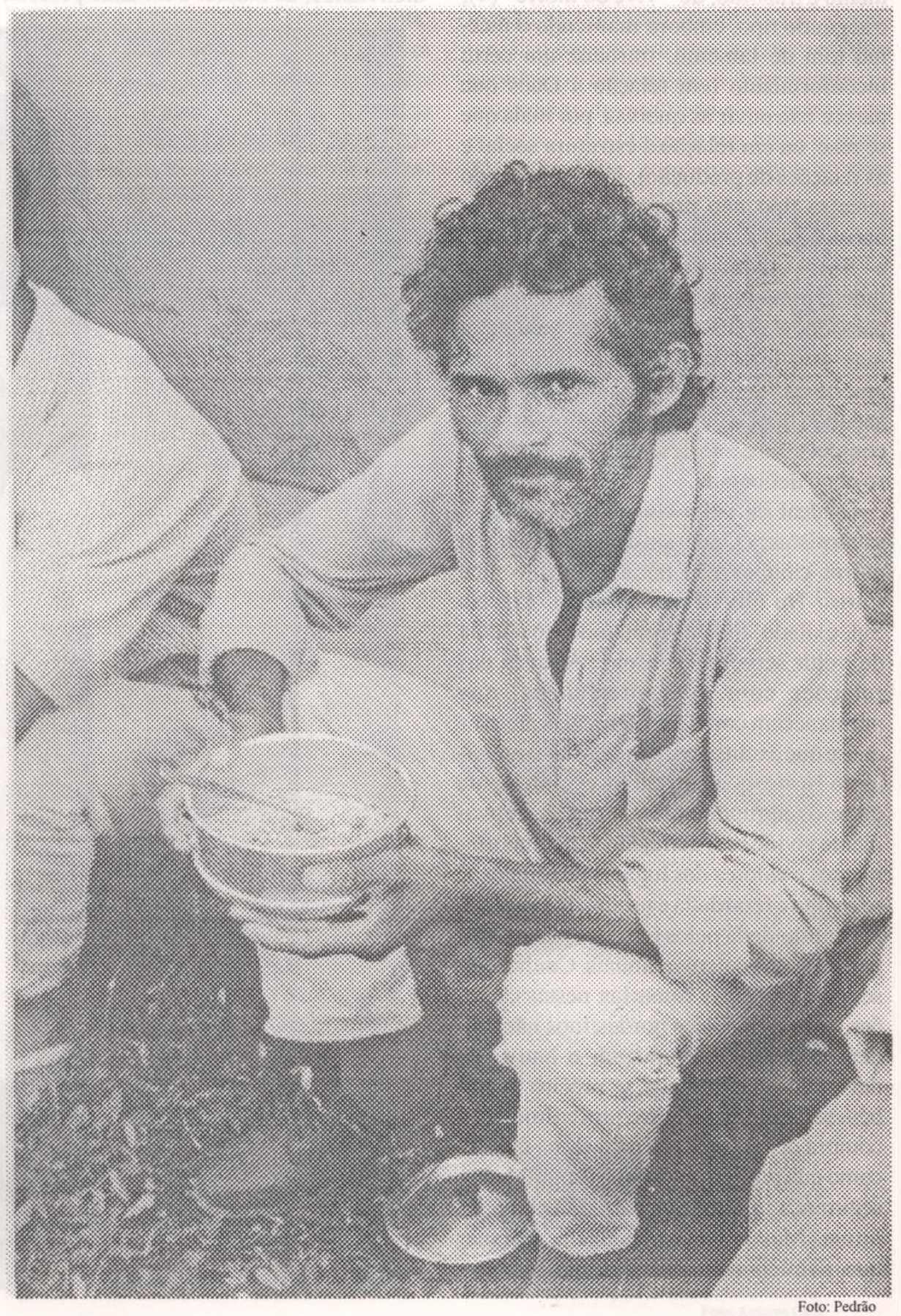


não são rigorosamente estanques: canções saudosistas, de lirismo ingênuo e fundo edênico; canções politizadas, líricas e esquemáticas na forma do "protesto"; canções afirmativas, em que a migração é efeito de decisão irreversível.

Enquanto o primeiro tipo opõe simplesmente o Norte (pintado como terra de abundância, autenticidade pessoal, bondade e felecidade espontânea, contanto que chova) ao Sul, como lugar de sofrimento e trabalho, de "vivê ou morrê"'(4), o segundo tipo, embora mantendo o mesmo tom de lamento, introduz um certo inconformismo (em relação a Deus que parece não ouvir as queixas, por mais que se reze, ou em relação à estrutura social e às relações de produção). Já as canções do terceiro tipo não procedem por simples oposição das virtudes e maldades de Norte e Sul; visam ao futuro de modo indeterminado, mantendo a referência ao passado na clave de um tempo completo, mas sem idealizações como ocorre nas anteriores. Se nas canções do primeiro e segundo tipos a vinda para o Sul ć forçada, compulsória e não desejada, nas do terceiro ela é deliberada.

$\mathrm{O}$ ideal da volta comanda as canções saudosistas: "Quem sai da terra natal/Em outros campos não pára/ Só deixo meu Cariri/ No último pau-de-arara"'(5). No Sul, exilado, tudo estranhando, só a idéia de volta serve de consolo. Através das relações com os conterrâneos, que parmanecem como as referências afetivas quase que exclusivas, pelas cartas e notícias do Norte, que correm incessantemente entre os agrupamentos, o que é efetivamente vivido está marejado dos comportamentos e valores dos lugares de origem. $\mathrm{E}$ se a volta é retardada e mesmo impossível, ela é abrandada pelos retornos periódicos, para as festas coletivas anuais. Conhecemse as verdadeiras romarias nestas ocasiões, para as quais os nordestinos não medem esforços; economizam o ano todo, deixando os empregos se preciso. Também se conhece um outro procedimento: a compra de terrenos, na roça ou na cidade, como que prefigurando uma estabilidade e segurança mínimas no caso da volta definitiva. Mas é preciso também acentuar que, paralelamente ao imaginário da vol- ta, outro se impõe: o da vivência e das possibilidades da cidade grande, o apelo do consumo, das facilidades (ainda que precárias) de educação e saúde, do futuro para os filhos. Só uma coisa permanece imutável e de difícil assimilação: a força da cultura de origem, mesmo quando edulcorada por emblemas de consumo e modernidade. Lembrar, rememorar é, então, não um simples passatempo, ou apego ao passado, mas o modo de estabilizar a afetividade; de manter a unidade pessoal, familiar e social; de fugir à fragmentação para não sucumbir à saudade, à loucura, à despersonalização.

Assim, uma primeira ambiguidade se impõe: lembrar é sempre preciso, mas é melhor ficar (como foi melhor partir) para não "ver tudo piorar"'(6). Ou seja, se o Norte permanece a referência da unidade, ficar no Sul é também uma proteção contra a imutabilidade das condições de vida do Norte. Por isso, geralmente quando retornam ao Norte, pretendendo ficar, logo

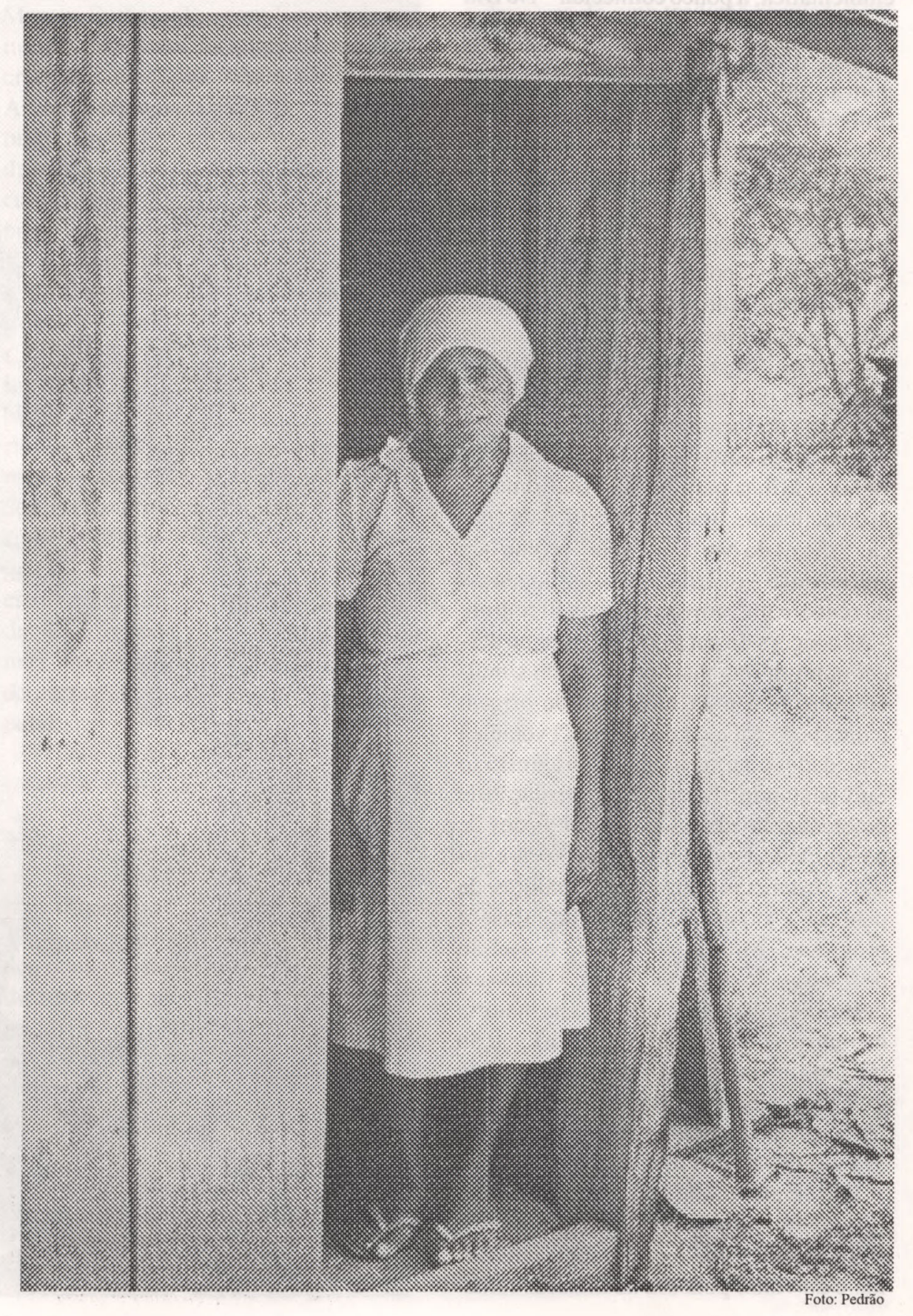

12 - Travessia - Setembro / Dezembro 93 
voltam, para tentar de novo.

As músicas politizadas manifestam, ao mesmo tempo, a saudade dos lugares de origem e os imperativos da participação, típicos dos anos 60. Provenientes de cantadores nordestinos ou de artistas articulados aos projetos culturais que faziam a crítica da dominação (do coronelismo, do imperialismo, do capitalismo)e, depois de 64, do Regime Militar, incidiam, nos temas, nos ritmos e melodias, nos processos de "conscientização" e de "protesto". Embora procedendo também idealização, seus objetivoseram didáticos: ensinar, esclarecer e mobilizar. A maior parte delas nasceu no interior dos movimentos (artísticos, da Igreja Católica, educacionais) instrumentados politicamente. Mesmo quando frutos do lirismo individualizado, ou dos cantadores, foram apropriados por projetos (como o dos Centros Populares de Cultura - CPC - da UNE; os de teatro, como nos shows "Opinião"'(1965), "Arena conta Zumbi", "Arena conta Bahia"); pelo cinema de Glauber Rocha e outros (inclusive pelos Festivais de Música Popular), que visavam a uma crítica dos sistemas de poder montando alegorias revolucionárias.

Embora as mensagens políticas traduzidas nas músicas fossem bombásticas, levantando as platéias (geralmente de intelectuais, estudantes e público variado das classes médias), seu efeito era mais emotivo que politicamente instaurador de práticas. Serviram, entretanto, na ocasião, para manter um fervor e entusiasmo na explicitação da miséria e injustiça reinantes. Serviram, por sua atitude "contra" para mobilizar corações e mentes na indignação. Canções como "Sina de Caboclo" (João do Vale, 1964) e "Borandá" (Edu Lobo, 1966) são típicas: ainda que melancólicas, indicam decisão, tomada de posição. João do Vale, músico nordestino que se tornou conhecido com a famosa "Carcará", cantada por Nara Leãoe Maria Bethânia no show "Opinião", - música que foi um dos emblemas maiores da luta contra o golpe de $64 \mathrm{e}$ tudo o que representou de dominação, repressão e conservadorismo-, é descritiva e incisiva: "Eu sou um pobre caboclo/ Ganho a vida na enxada/O que eu colhoé dividido/ Com quem não plantô nada. Se assim continuá/ Vou deixar o meu sertão/ Mesmo os olhos cheios d'água/E com dor no coração. Vou pro Rio carregá massa/ Pros pedreiro em construção.(...)Mas plantá pradividi/Não faço mais isso não". Este refrão, como o de "Carcará" ("Pega, mata e come") e o de "Opinião", de Zé Keti ("Podem me prender/ Podem me bater/ Podem até deixar-me sem comer/ Que eu não mudo de opinião"'), virou símbolo de mensagem participativa. Em cada um desses refrões ouve-se a voz do dominado que se revolta, na voz do artista que fala em nome dos que não têm voz. Na ocasião, este procedimento didático repercutiu e foi contundente, apesar de toda a crítica que se possa fazer ao seu conteúdo ideológico simplista.

Na música citada de Ėdu Lobo percebese um nível de ambiguidade já bastante nítido, certamente devido à proveniência do artista (instruído, da classe média da zona sul do Rio). O protesto não é direto, visando a instrumentar revolta; é subliminar: vamos embora, andar, "que a terra já secou/ que a chuva não chegou" e “'meu Deus não ouve, não". É um lamento, assim refoçado: "Vou-me embora, vou chorando/ Vou me lembrando/ do meu lugar". Mas: "Quanto mais eu vou pra longe/ Mais eu penso sem parar/ Que é melhor partir lembrando/ Que ver tudo piorar ". A lembrança não implica necessariamente saudade: parte-se porque a situação é irremediável, só tende a piorar. O protesto insinua-se dramaticamente, na alusão ao estado estagnatário do Norte (do Brasil, alegoricamente). Disso advém a ambiguidade; partir nãoé, necessariamente, um mal: é decisão proveniente de análise da situação; a contrapartida da dor de partir é a dor de ficar presenciando a desgraça. Ao consentimento destrutivo na dor de ficar opõe-se a força da vida: partir. Esta abertura para o futuro, ainda melancólica, desemboca no elogio da mudança pelo correr "no meio do mundo" na música "Ponteio", feita com Capinam, e ganhadora do III Festival de MPB da TV Record em 1967. Nela, embora o tema não seja o do retirante, mas o da eficácia do canto em meio à "violência" eà "morte" se diz: "Parado no meio do mundo/ Senti chegar meu momento/ Olhei pro mundo e nem via/ Nem sombra, nem sol, nem vento". Daí surge a esperança de mudança: "Certo dia que sei por inteiro/ Eu espero não vá demorar/ Esse dia estou certo que vem/ Digo logo o que vim pra buscar". Alegoricamente, a decisão de partir abre a possibilidade da transformação, elidindo a dor através do combate.

A ambiguidade assinalada, que matiza a mitologia da volta, na verdade já se manifestava no Caymmi de "Peguei um Ita no Norte", mesmo em "Saudade da Bahia". Nos versos: "Vendi meus troços que eu tinha/ O resto eu dei pra guardar/ Talvez eu volte pro ano/ Talvez eu fique por lá", flagram-se dois índices de relativização desse mito: o óvio talvez e o modo da enunciação. Caymmi duvida da volta mesmo antes de ir. Depois, mudando o tempo verbal, reitera o que estava implícito na dúvida: "Tou há bem tempo no Rio/ Nunca mais voltei por lá/ Pro mês inteiro é dez anos/ Adeus Belém do Pará"'. A música é puramente descritiva, não constrói estados de alma, não há saudade nela; é antiilusionista. Em "'Saudade da Bahia", embora o tema seja a saudade e um certo lamento, - pois " se escutasse o que mamãe dizia" não teria partido, não teria saudade da Bahia, e embora diga que "pobre de quem acredita/ na fama e no dinheiro para ser feliz" (entenda-se, o que se procura no Sul) -, ele observa: "a gente faz o que o coração dita"; isto é, "esse mundo é feito de maldade e ilusão", mas a gente faz o queé imperioso, o queé ditado pelo desejo. $\mathrm{E}$ aí, nem a saudade tem poder; pode-se apenas "desabafar", transformar o sofrimento representando-o na linguagem e no canto. Em Caymmi é bem claro que não há nunca volta: parte-se por decisão, por imposição de construir a vida para além da melancolia. Com seu lirismo descritivo Caymmi é tranquilo e feliz num presente contínuo

Em "Triste Partida" há também um indice interessante: falando do "nortista, tão forte, tão bravo"', observa que dá pena vê-lo "vivê como escravo/ No Norte e no $\mathrm{Su}$ ". Faz, na música, um inventário das desgraças do Norte e da dor de partir; mas também da vida em São Paulo onde "Trabaia dois ano/ Três ano e mais ano/E sempre nos pranos/ De um dia voltá. Mas 
nunca ele pode, só vive devendo/ e assim vai sofrendo/ A sofrê sem pará''(...) O tempo rolando, vai dia, vem dia/ E aquela famia/ Não volta mais não". A desilusão acaba em desistência; pois tanto faz no Sul como no Norte, é tudo igual. O mito da volta é destruído pelo princípio de realidade. E, na famosa "Paraíba" (Luiz Gonzaga e Humberto Teixeira, 1962) a partida é deliberada e sem dramas, como fica indiciado no "vim 'embora": "Quando a lama virou pedra/ E mandacaru secou/ Quando ribaçã de sede/ Bateu asas e vuou/ Eu entonce vim'embora/ Carregando minha dor'. A ausência de drama é reiterada quando diz que " meu bodoque num quebrou" e que hoje apenas manda "um abraço/ Pra ti pequenina/ Paraíba masculina/ muié macho, sim senhor',

É no Tropicalismo dos anos 1967/68 que as ambiguidades rastreadas se radicalizam, configurando em sua plenitude o terceiro tipo de canções que tratam da partida para o Sul. O tema é explorado sem recurso a nostalgias, melancolia e depressão. São músicas afirmativas; incidem sobre o presente, abertas para um futuro imponderável e que tomam o passado, o Norte, a Bahia, como fonte de valor incontestável, pois deu a seus filhos "régua e compasso", (Gilberto Gil, "Aquele Abraço"). Mas: "'adeus, meu bem, eu não vou mais voltar' (Caetano Veloso, “Quem me dera')' Há mudança radical no tema da volta e no registro das canções, agora acolhendo a modernização (social, política, cultural, artística) como positividade e desafio. Longe dos versos e acordes saudosistas, o que nelas se vê é a coragem de viver o heterogêneo, o mutável; sem ideais fixados, só com perspectivas.

Embora a Bahia esteja presente em muitas das canções do Grupo Tropicalista (Caetano, Gil, Torquato Neto, Capinam, Tom Zé), numa delas o tema do migrante está tratado de modo exemplar: "No dia que eu vim-me embora', , de Caetano e Gil (1968). Nesta música, o rigor de linguagem produz imagens precisas, compondo o imaginário da partida fincado numa mitologia privada de rara argúcia e, pela primeira vez na música popular, pensando a partida como ruptura, sem qualquer referência ao que deixava. É verdade que tem muito de similar a "Peguei um Ita no Norte", mas é mais complexa, radical e cruel, pois nela o sentimento está objetivado. Vale a pena transcrevê-la na íntegra para se acentuar a sua eficácia crítica:

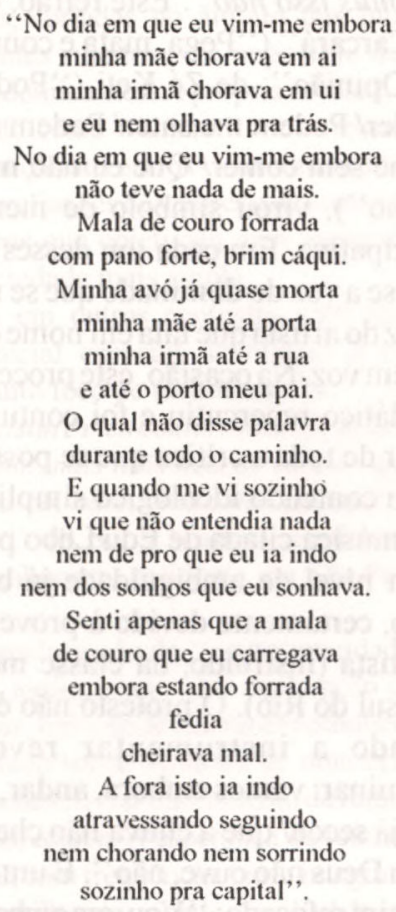

Desde o primeiro verso acentua-se 0 ato voluntário ("vim-me embora"), indiciando escolha e determinação; a saudade não se impõe: a partida "não teve nada de mais". Diferentemente das demais músicas rastreadas, não há remissão aos lamentos familiares; não há conselhos também: a mãe e a irmã choravam, a avó " "já quase morta" e o pai "não disse palavra", mas " "eu nem olhava pra trás". Cru e cruel, diz que a mala de couro (o passado, a família, o lugar de origem) "fedia, cheirava mal"; isto é, o passado é associado à morte e decomposição, dada a sua imutabilidade. A esta atitude antepõe-se a abertura para o presente, o que é indiciado pelo tempo verbal, presente contínuo: "ia indo, atravessando, seguindo, nem chorando, nem sorrindo": plena disponibilidade para o acontecimento, para o indeterminado. Parte "sozinho pra capital", sem mitificar o passado, sem apoiar-se em utopias de futuro. Sem construir mitologia coletiva, sem vincular-se a qualquer projeto pré-fixado, lança-se no puro fluir do tempo, convertendo a própria individualidade em mito.
Esta canção, considerada no conjunto das demais canções e intervenções tropicalistas, produz um deslocamento dos temas tradicionais da música popular brasileira, no lirismo e na participação, tanto no que se refere aos conteúdos (sentimentos, afetos, significações políticas, sociais e morais) quanto aos procedimentos artísticos. A canção não é apenas expressão de sentimentos, valores e tomadas de posição, fonte de lirismo e prazer, mas um pensamento que corrói os sujeitos instituídos. O discurso político e a crítica social não aparecem nessas canções sob a forma de uma pedagogia, derivada de uma doutrina (ideologia), antes propõem-se como intersecção de discursos e práticas que se relativisam mutuamente

Assim, o tema do migrante, por exemplo, não contempla nem a saudade nem o ideal de volta, pois a migração é imaginada como exercício desterritorializante, isto é, como abertura para a vida, para o mundo e suas surprezas.

Sintomaticamente, depois da crítica tropicalista o tema do migrante não alcançou outras expressões significativas; sintoma, talvez, das transformações radicais que a imersão do país na modernização capitalista provocou. Mesmo que o Norte continue idealizado para os migrantes, as formas sociais do Sul, principalmente a sedução dos bens de consumo e os ardis da comunicação, reduziram a saudade e o desejo de volta a elementos de um álbum de fotografias ou a despojos de um tempo onde ainda havia felicidade.

* Celso F. Favaretto é Mestre e Doutor em Filosofia pela USP, Professor na Faculdade de Educação da USP, autor de Tropicália: Alegoria, Alegria (S.Paulo, Kairós, 1979) e A Invenção de Hélio Oiticica (S.Paulo, EdUSP, 1992).

\section{NOTAS}

(1) Dorival Caymmi, "Saudade da Bahia", 1957. "Peguei um Ita no Norte" é de 1945, e a de Caetano(e Gil) de 1968.

(2) Luiz Gonzaga e Humberto Teixeira, "Asa Branca", 1952 .

(3) A distinção é de Walnice Nogueira Galvão, em "MPB: uma análise ideológica". In - APARTE, TUSP, maio-junho 1968.

(4) Cf. "A Triste Partida", de Patativa do Assaré, 1965.

(5) "O último pau-de-arara", de Venâncio, Corumba e J. Guimarães, 1956

(6) "Borandá", de Edu Lobo, 1966. 